\title{
Stretch and Physical Properties of Weft Stretch Denim Fabrics Containing Elastane and Filament Yarn
}

\author{
Yusuf Daşan and Osman Babaarslan* \\ Çukurova University, Turkey
}

*Corresponding author: Osman Babaarslan, Çukurova University, Engineering Faculty, Department of Textile Engineering, 01330 Balcalı/Adana, Turkey.

Received Date: December 17, 2019

Published Date: January 16, 2020

\begin{abstract}
In recent years, as a result of the combination of textile materials with different structures and characteristics by using different production methods, yarn and fabric designs with new features have become important. In this study, the effect of cotton wrapped elastic dual core-spun yarns containing elastane and filament on the performance properties of denim fabrics was investigated. Denim fabrics were produced that used in the weft direction of cotton wrapped elastic dual core-spun yarns containing different types filaments and different ratios of elastane in the core. Performance tests conforming to the standards were applied on denim fabrics. In addition, variance and regression analyzes were carried out using the MINITAB package program to evaluate the effects on the fabric performance properties that are believed to originate from dual core-spun weft yarns. The effects of process factors on the fabric properties were expressed using mathematical models.
\end{abstract}

Keywords: Dual core-spun yarn; Denim fabric; Elasticity; Growth; Shrinkage; Statistical model

\section{Introduction}

Elasticity is known as an important feature in clothes. From the user's point of view, comfort and mobility are enhanced by elasticity. The flexible denim fabrics that surround the body at this point are attract intensive attention today. But the uncontrolled increase of elasticity causes some problems for clothing. One of the most important problems with elasticity in garments is deformities and wrinkles [1]. The increase of fabric growth and shrinkage rate affect the comfort properties of the clothes negatively and cause deformities. As a result, the lifetime and the quality of the clothes decrease. While strength and elasticity are particularly desirable in denim fabrics, high growth and shrinkage are an undesirable feature. Some studies conducted in this area are available in the literature.

Baykus D [2], produced woven fabrics with different constructions of cotton/elastane, cotton/polyester/elastane, and polyester/viscon/elastane blends. After the different end treatments applied, they determined the improvement of shrinkage, elasticity and growth values. They also revealed that the increase in weft and warp frequency improves the growth values.
Babaarslan 0, et al. [3], investigated the effects of the elastane core yarn on the strength and elongation properties of the fabric. They found that with elastane core-spun yarns improve the strength and elongation properties of the woven fabrics.

Ozdil N [1] compared the performance characteristics (breaking strength, tear strength, bagging and bending properties) of five different denim fabrics containing different ratios elastane. Due to the increase in elastane ratio in the denim fabric it was found that the elasticity increases, the strength and the permanent bagging values decrease.

El-Ghezal S, et al. [4] conducted a study to investigate the effects of different elastane ratio and finishing processes on denim fabric properties. In the study conducted, they emphasized that the elastane ratio significantly influences the mechanical properties of the fabric. In addition, they also found that the different end treatments applied in the study affected the elasticity and mechanical properties of the fabric in a unique way.

Adeli B, et al. [5], studied the physical and visual changes that occurred in the core-spun yarn and core-spun containing fabric 
after repeated loading. Within the scope of the study, sample fabrics were produced from core-spun yarns produced with 5 different elastane draw ratios. 500, 1000 and 1500 repetitive loading tests were applied to these fabrics. As a result of the study, it was found that the sample group with an elastane draw ratio of 2.9 showed the lowest elongation ability while the sample group with an elastane draw ratio of 3.9 showed the best elongation ability at the end of 1000 repetitions.

Mourad M [6], produced woven fabrics containing elastane in different proportions. Using statistical methods, examined the effect of the ratio of elastane on cotton fabric properties. It was found that the change in elastane ratio has a significant effect on the physical and tensile properties of cotton woven fabrics.

Studies on estimating the mechanical properties of fabrics using developed mathematical models are available in the literature as well.

Models have been developed to measure warp and weft density of high-strength twill and satin fabrics. The relationship between the weft and warp density through the texture structure of the produced fabrics was established and the unit density with the developed model was determined [7].

Zhang X, et al. [8], developed a mathematical model and investigated the physical mechanism of fabric bagging. They developed an equation that relates the bagging strength to the fabric tensile strength for to be predict fabric bagging performance.

Maqsood Q, et al. [9], investigated the properties of bi-stretch woven fabrics. They have used taguchi gray relational analysis method (GRA) to determine the optimum quality parameters of fabrics of different structures woven using elastane core-spun yarns in the direction of weft and warp. Using this method, the elastane linear density, weft/warp density, and weaving structure factors were found to influence the fabric properties.

By maintaining stretch properties of denim fabrics which are given high elasticity by elastane, it is possible to continue the permanence of stretchiness during usage. For this purpose, different elastomultiester fibers are using together with elastane. In this study, stretch fabrics with stretch properties were fabricated to utilize the properties of alternate fibers to reduce the permanent elongation values and protect the form. Thus, it is aimed to keep undesirable properties such as growth and shrinkage at a minimum level while bringing important characteristics such as usage performance and elasticity to an optimum level in denim fabrics. Denim fabrics were produced with elastic core-spun (dual corespun) weft yarns developed for this purpose. Fabric performance tests were carried out and the results obtained were evaluated.

\section{Material and Method}

Within the scope of this study, twelve different elastic dual corespun yarns which is wrapped with cotton fibers and which have elastane and filament in the core, were produced. The properties of the cotton fiber and core components of elastic dual core-spun yarns are given in Table 1.

Table 1: Fiber and filament yarn characteristics.

\begin{tabular}{|c|c|c|c|c|c|}
\hline \multirow{2}{*}{ Characteristics } & \multicolumn{5}{|c|}{ Values } \\
\cline { 2 - 6 } & Cotton & Xanadu ${ }^{\circ}$ & PES & PA6.6 & Elastane \\
\hline $\begin{array}{c}\text { Fineness (mic) } \\
\text { / Linear density } \\
\text { (dtex) }\end{array}$ & 4,56 & 83 & 83 & 83 & 78 \\
\hline $\begin{array}{c}\text { Strength (g/d) } \\
\text { Elongation (\%) }\end{array}$ & 3.56 & 4.28 & 3.96 & 4.3 & 1.09 \\
\hline Length (mm) & 28.53 & - & - & - & - \\
\hline Uniformity Index & 85.04 & - & - & - & - \\
\hline $\begin{array}{c}\text { Spinning Consisten- } \\
\text { cy Index }\end{array}$ & 128 & - & - & - & - \\
\hline Short Fiber Index & 8 & - & - & - & - \\
\hline
\end{tabular}

The characteristics of the filament types that are present with elastane in the core of the elastic dual core-spun yarns are different from each other. Xanadu exhibits elastane like properties in terms of flexibility. In addition, it has a more crimped structure than polyester and nylon filament [10].

Elastic dual core-spun yarns were produced using a ring spinning machine with modification. The yarn linear density in production was Ne 14 (42 tex) and the twist coefficient $\alpha$ e 4.5. Elastane draw ratios were selected as 3.0 (300\%), 3.5 (350\%), 4.0 $(400 \%)$ and $4.5(450 \%)$. Filament draw ratio was $1.08(8 \%)$. The coding and test results of the produced yarns are given in Table 2.

Table 2: Properties of elastic dual core-spun yarns.

\begin{tabular}{|c|c|c|c|c|c|c|c|c|c|c|}
\hline $\begin{array}{l}\text { Sample } \\
\text { No }\end{array}$ & $\begin{array}{l}\text { Elastic dual } \\
\text { core-spun yarns }\end{array}$ & $\begin{array}{c}\text { Yarn linear } \\
\text { density } \\
\text { (tex) }\end{array}$ & $\begin{array}{c}\text { Filament } \\
\text { linear } \\
\text { density } \\
\text { (dtex) }\end{array}$ & $\begin{array}{c}\text { Filament } \\
\text { draw ratio }\end{array}$ & $\begin{array}{c}\text { Elastane } \\
\text { linear } \\
\text { density } \\
\text { (dtex) }\end{array}$ & $\begin{array}{c}\text { Elastane } \\
\text { draw ratio }\end{array}$ & $\begin{array}{l}\text { Twist per } \\
\text { meter }\end{array}$ & $\begin{array}{l}\text { Tenacity } \\
\text { (cN/tex) }\end{array}$ & $\begin{array}{c}\text { Elongation } \\
(\%)\end{array}$ & CVm (\%) \\
\hline 1 & $\mathrm{CO}+\mathrm{Xa}+\mathrm{EL}$ & 42 & 83 & 1.08 & 78 & 3.0 & 660 & 15,21 & 10,31 & 12,17 \\
\hline 2 & $\mathrm{CO}+\mathrm{Xa}+\mathrm{EL}$ & 42 & 83 & 1.08 & 78 & 3,5 & 660 & 15,03 & 10,36 & 12,49 \\
\hline 3 & $\mathrm{CO}+\mathrm{Xa}+\mathrm{EL}$ & 42 & 83 & 1.08 & 78 & 4.0 & 660 & 15,11 & 10,40 & 12,53 \\
\hline 4 & $\mathrm{CO}+\mathrm{Xa}+\mathrm{EL}$ & 42 & 83 & 1.08 & 78 & 4,5 & 660 & 14,98 & 11,21 & 12,37 \\
\hline 5 & $\mathrm{CO}+\mathrm{PES}+\mathrm{EL}$ & 42 & 83 & 1.08 & 78 & 3.0 & 660 & 12,96 & 9,53 & 12,67 \\
\hline 6 & $\mathrm{CO}+\mathrm{PES}+\mathrm{EL}$ & 42 & 83 & 1.08 & 78 & 3,5 & 660 & 14,17 & 9,86 & 12,54 \\
\hline 7 & $\mathrm{CO}+\mathrm{PES}+\mathrm{EL}$ & 42 & 83 & 1.08 & 78 & 4.0 & 660 & 14,30 & 9,98 & 12,46 \\
\hline 8 & $\mathrm{CO}+\mathrm{PES}+\mathrm{EL}$ & 42 & 83 & 1.08 & 78 & 4,5 & 660 & 14,03 & 9,48 & 12,50 \\
\hline
\end{tabular}




\begin{tabular}{|c|c|c|c|c|c|c|c|c|c|c|}
\hline 9 & CO + PA6.6 + EL & 42 & 83 & 1.08 & 78 & 3.0 & 660 & 12,45 & 9,75 & 12,89 \\
\hline 10 & CO + PA6.6 + EL & 42 & 83 & 1.08 & 78 & 3,5 & 660 & 13,33 & 10,00 & 12,80 \\
\hline 11 & CO + PA6.6 + EL & 42 & 83 & 1.08 & 78 & 4.0 & 660 & 13,46 & 9,82 & 12,44 \\
\hline 12 & CO + PA6.6 + EL & 42 & 83 & 1.08 & 78 & 4,5 & 660 & 14,89 & 11,20 & 12,58 \\
\hline
\end{tabular}

Elastic dual core-spun yarns composed of different core components in the same linear density were used as weftyarns in the fabric, and denim fabrics were produced in the same construction. In the warp, indigo dyed Ne 10/1 (59 tex) 100\% cotton yarn was used. Denim fabric samples were produced in the "Dornier htws 4/ S16" brand rapier weaving machine. The production parameters of the denim fabrics are given in Table 3.

Table 3: Weaving parameters.

\begin{tabular}{|c|c|}
\hline Machine speed & $\mathbf{4 8 0} \mathbf{~ r p m}$ \\
\hline Reed number & $60,8 / 4$ \\
\hline Reed width & $178 \mathrm{~cm}$ \\
\hline Warp yarn & Ne $10 / 1, \alpha \mathrm{e}: 4,5$ \\
\hline Warp density & 24 warp yarn/cm \\
\hline Weft yarn & Ne $14 / 1, \alpha \mathrm{e}: 4,5$ \\
\hline Weft density & 21 weft yarn/cm \\
\hline Weave type & Twill 3/1 z \\
\hline
\end{tabular}

Three groups of denim fabrics were produced with different filament core materials. The first groups were produced with elastic dual core-spun weft yarns with 78 dtex elastane and 83 dtex xanadu (Xa) filament in the core. The second groups were produced with elastic dual core-spun weft yarns with 78 dtex elastane and 83 dtex polyester (PES) filament in the core. The last groups were produced with elastic dual core-spun weft yarns with 78 dtex elastane and 83 dtex nylon (PA6.6) filament in the core.

After weaving, fabric samples were subjected to burning (cauterization), mercerization (caustic $\mathrm{NaOH}-18^{\circ} \mathrm{Bè}$ ), polyacrylic softening and sanforization. The sample denim fabrics were tested to quality control according to ASTM D 1776 after conditioning at standard atmospheric conditions. According to ASTM D 5035 standard test method, breaking strength test was performed on weft and warp direction. Size change tests were carried out according to AATCC135/ISO 633. Also, elongation test, elasticity and growth tests according to ASTM D 3107 were applied to the sample denim fabrics.

According to the relevant standard, the elongation test was applied to the fabric samples in the warp direction. One of the test samples taken from the fabrics was attached to the upper jaw of the test device and the jaw was fixed. The other end of the sample fabric was attached to the lower jaw block weighing $1.36 \mathrm{~kg}$. The lower jaw block was slowly released for 5 seconds, the sample was stretched, and this process was repeated three times. For the fourth time, the lower jaw was released and the distance between the two points was read within 10 seconds.

Once again according to the relevant standard, the elasticity test was applied to the washed sample fabrics in the direction of the weft. One of the test samples taken from the fabrics was attached to the upper jaw of the test device and the jaw was fixed. The other end of the sample fabric was attached to the lower jaw block weighing $1.36 \mathrm{~kg}$. The lower jaw block was slowly released for 5 seconds, the sample was stretched, and this process was repeated three times. For the fourth time, the lower jaw was released and the distance between the two points was read after $30 \pm 0.5$ minutes.

The growth test was applied to the washed fabric samples in the direction of the weft. The application steps are the same as the other reversals. Finally, the test samples were removed from the instrument and rested on a flat surface. The size of the test sample was measured after $120 \pm 1$ minutes.

The measured values were evaluated using the following equation (1)

Denim Fabric Elongation $\%=\frac{\text { Last Length }- \text { First Length }}{\text { First Length }} \times 100$ (1)

The type of filament $\left(t_{1}\right)$, the elastane draw ratio $\left(t_{2}\right)$ and the ratio of elastane in the fabric $\left(\mathrm{t}_{3}\right)$ are the variables considered in this study. The state of these variables in the sample fabrics is given in Table 4.

Table 4: Sample fabric variables (process factors).

\begin{tabular}{|c|c|c|c|c|}
\hline $\begin{array}{l}\text { Sample } \\
\text { No }\end{array}$ & $\begin{array}{l}\text { Filament } \\
\text { type }\left(t_{1}\right)\end{array}$ & $\begin{array}{l}\text { Elastane } \\
\text { draw }\left(t_{2}\right)\end{array}$ & $\begin{array}{c}\text { Elastane Ratio } \\
\left(\mathrm{t}_{3}\right)(\%)\end{array}$ & Weave type \\
\hline 1 & \multirow{4}{*}{ Хa } & 3 & 2.37 & \multirow{12}{*}{ 3/1, Z twill } \\
\hline 2 & & 3.5 & 2.03 & \\
\hline 3 & & 4 & 1,78 & \\
\hline 4 & & 4.5 & 1.58 & \\
\hline 5 & \multirow[t]{4}{*}{ PES } & 3 & 2.37 & \\
\hline 6 & & 3.5 & 2.03 & \\
\hline 7 & & 4 & 1,78 & \\
\hline 8 & & 4.5 & 1.58 & \\
\hline 9 & \multirow{4}{*}{ PA 6.6} & 3 & 2.37 & \\
\hline 10 & & 3.5 & 2.03 & \\
\hline 11 & & 4 & 1,78 & \\
\hline 12 & & 4.5 & 1.58 & \\
\hline
\end{tabular}

Variance and regression analyze were carried out using the MINITAB package program to evaluate the effects on the fabric performance characteristics that are believed to originate from dual core-spun weft yarns. Analysis of variance reveals whether the difference between process factors is significant in general. In addition, mathematical models were developed to demonstrate the magnitude of the interaction between process factors and factors on denim fabric properties. 


\section{Results and Discussion}

Performance characteristics of fabrics weaved using elastic dual core-spun yarns with filament and elastane in different properties were examined. Three different samples were prepared for each type of fabric samples against quality control tests in accordance with the relevant standards. The mean values obtained after the tests made are given in Table 5.

Table 5: Test results of denim fabrics.

\begin{tabular}{|c|c|c|c|c|c|c|c|c|c|}
\hline $\begin{array}{c}\text { Sample } \\
\text { No }\end{array}$ & $\begin{array}{c}\text { Fabric width } \\
\text { off loom (cm ) }\end{array}$ & $\begin{array}{c}\text { Elongation } \\
\mathbf{( \% )}\end{array}$ & $\begin{array}{c}\text { Elasticity } \\
\mathbf{( \% )} \mathbf{1 . 3 6} \\
\mathbf{~ k g}\end{array}$ & $\begin{array}{c}\text { Growth } \\
\mathbf{( \% )}\end{array}$ & $\begin{array}{c}\text { Warp } \\
\text { direction } \\
\text { strength } \\
\text { (kgf) }\end{array}$ & $\begin{array}{c}\text { Weft } \\
\text { direction } \\
\text { strength } \\
\text { (kgf) }\end{array}$ & $\begin{array}{c}\text { Shrinkage in } \\
\text { warp direction } \\
\mathbf{( \% )}\end{array}$ & $\begin{array}{c}\text { Shrinkage in } \\
\text { weft direction } \\
\text { (\%) }\end{array}$ & $\begin{array}{c}\text { Finished fabric } \\
\text { width (cm) }\end{array}$ \\
\hline 1 & 126.5 & 11.6 & 28 & 2.0 & 86 & 47 & -3.0 & -10.0 & 113.9 \\
\hline 2 & 124.5 & 9.4 & 33.2 & 2.4 & 84 & 47 & -4.0 & -10.0 & 112.1 \\
\hline 3 & 124.1 & 9.6 & 34.8 & 2.0 & 83 & 50 & -3.4 & -12.0 & 109.2 \\
\hline 4 & 124 & 10.8 & 32.0 & 2.4 & 86 & 48 & -3.0 & -11.0 & 110.4 \\
\hline 5 & 133.5 & 11.0 & 32.0 & 4.0 & 76 & 45 & -3.0 & -11.0 & 118.8 \\
\hline 6 & 129.8 & 10.4 & 34.0 & 4.8 & 85 & 47 & -4.0 & -11.0 & 115.5 \\
\hline 7 & 126 & 11.6 & 34.8 & 4.0 & 79 & 45 & -3.0 & -11.6 & 111.4 \\
\hline 8 & 127.8 & 11.6 & 38.0 & 4.8 & 86 & 45 & -2.0 & -12.0 & 112.5 \\
\hline 9 & 131.5 & 11 & 29.6 & 6.0 & 83 & 44 & -3.8 & -11.2 & 116.8 \\
\hline 10 & 129 & 9.6 & 40.8 & 4.0 & 91 & 45 & -6.0 & -16.0 & 108.4 \\
\hline 11 & 128.6 & 9.0 & 39.6 & 4.8 & 83 & 44 & -6.0 & -16.1 & 107.9 \\
\hline 12 & 126 & 9.4 & 40.0 & 5.6 & 85 & 46 & -5.6 & -16.2 & 105.6 \\
\hline
\end{tabular}

Statistical analysis of the results was performed using the MINITAB statistical analysis program. In the study, regression analysis was performed to quantify the interaction between denim fabric properties (elongation, elasticity, growth, etc.), and process

factors (filament type $\left(t_{1}\right)$, elastane draw ratio $\left(t_{2}\right)$, elastane ratio $\left(t_{3}\right)$ ). The regression coefficient and p-values obtained after the analysis are given in Table 6.

Table 6: Regression coefficients for denim fabric response variables using values of the t1. t2. t 3 variables.

\begin{tabular}{|c|c|c|c|c|c|c|c|c|c|c|c|c|c|c|}
\hline \multirow[b]{2}{*}{ Terms } & \multicolumn{2}{|c|}{$\begin{array}{c}\text { Elongation( } \\
\% \text { ) }\end{array}$} & \multicolumn{2}{|c|}{$\begin{array}{c}\text { Elasticity( \% ) } \\
1.36 \mathrm{~kg}\end{array}$} & \multicolumn{2}{|c|}{$\begin{array}{c}\text { Growth ( \% ) } \\
1.36 \mathrm{~kg}\end{array}$} & \multicolumn{2}{|c|}{$\begin{array}{l}\text { Warp breaking } \\
\text { strength (kgf) }\end{array}$} & \multicolumn{2}{|c|}{$\begin{array}{l}\text { Weft breaking } \\
\text { strength (kgf) }\end{array}$} & \multicolumn{2}{|c|}{$\begin{array}{l}\text { Finished fabric } \\
\text { shrinkage in } \\
\text { warp direction } \\
(\%)\end{array}$} & \multicolumn{2}{|c|}{$\begin{array}{c}\text { Finished fabric } \\
\text { shrinkage in } \\
\text { weft direction } \\
(\%)\end{array}$} \\
\hline & Coef. & P-Value & Coef. & P-Value & Coef. & P-Value & Coef. & P-Value & Coef. & P-Value & Coef. & P-Value & Coef. & P-Value \\
\hline Constant & 10.98 & $0.000^{*}$ & 37.72 & $0.000^{*}$ & 3.9 & $0.000^{*}$ & 75.88 & $0.000^{*}$ & 45.64 & $0.000^{*}$ & -3.07 & $0.000^{*}$ & -12.21 & $0.000^{*}$ \\
\hline $\mathrm{t}_{1}$ & 0.25 & $0.012^{*}$ & -0.17 & 0.862 & -1.48 & $0.000^{*}$ & 1.7 & 0.316 & 3.83 & $0.000^{*}$ & 1.09 & $0.005^{*}$ & 0.63 & 0.321 \\
\hline $\mathrm{t}_{2}$ & 1.63 & 0.113 & 0.98 & 0.697 & -0.78 & 0.203 & -23.31 & $0.000^{*}$ & -0.73 & 0.761 & 2.4 & $0.017^{*}$ & -1.55 & 0.358 \\
\hline $\mathrm{t}_{3}$ & 1.84 & 0.08 & -1.58 & 0.541 & -0.88 & 0.163 & -24.54 & $0.000^{*}$ & -1.02 & 0.678 & 2.48 & $0.015^{*}$ & -0.72 & 0.675 \\
\hline $\mathrm{t}^{2}$ & -0.75 & $0.000^{*}$ & -0.72 & $0.030^{*}$ & -0.51 & $0.000^{*}$ & 2.57 & $0.000^{*}$ & 0.54 & $0.003^{*}$ & -0.91 & $0.000^{*}$ & -0.86 & $0.000^{*}$ \\
\hline $\mathrm{t} 2^{2}$ & 0.17 & 0.532 & -1.97 & $0.008^{*}$ & 0.51 & $0.004^{*}$ & 5.79 & $0.000^{*}$ & -0.14 & 0.828 & 0.04 & 0.869 & 0.67 & $0.145^{*}$ \\
\hline $\mathrm{t}_{1}{ }^{*} \mathrm{t}_{2}$ & 1 & 0.485 & 9.64 & $0.012^{*}$ & -2.62 & $0.005^{*}$ & 14.43 & $0.030^{*}$ & 9.26 & $0.011^{*}$ & 0.83 & 0.544 & -6.09 & $0.016^{*}$ \\
\hline $\mathrm{t}_{1}^{*} \mathrm{t}_{3}$ & 0.87 & 0.567 & 11 & $0.007^{*}$ & -2.79 & $0.005^{*}$ & 14.92 & $0.034^{*}$ & 9.62 & $0.013^{*}$ & 0.59 & 0.682 & -6.93 & $0.010^{*}$ \\
\hline $\mathrm{t}_{1} * \mathrm{t}_{2} * \mathrm{t}_{3}$ & 0 & 1.000 & 2.22 & $0.029^{*}$ & -0.3 & $0.010^{*}$ & 2.22 & 0.203 & 2.47 & $0.012^{*}$ & 0.3 & 0.422 & -1.12 & $0.090^{*}$ \\
\hline
\end{tabular}

*Statistically significant terms with $95 \%$ confidence level.

The regression coefficient (coef.) specifies the magnitude of the effect $(+)$ or (-). A P-value less than 0.05 indicates a statistically significant effect on the $95 \%$ confidence interval. Table 6 shows that the data obtained in general are statistically significant. The ratio of the process variables $\left(t_{1}, t_{2}, t_{3}\right)$ in the denim fabric production to the fabric properties is expressed as $\mathrm{R}^{2}(\%) . \mathrm{R}^{2}$ value is the multiple regression between different parameters and the decision-making coefficient of the relationship.

According to statistical analysis, the quadratic model was chosen to determine the relationship between denim fabric properties and process factors. Regression equations were obtained in the study. These mathematical models and $\mathrm{R}^{2}$ values are given in Table 7 .

$\mathrm{R}^{2}$ values of more than $50 \%$ indicate that the mathematical equations obtained with the process variables $\left(t_{1}, t_{2}, t_{3}\right)$ have a high predictability of the produced denim fabric properties.

\section{Elongation, Elasticity and Growth}

The effect of change in filament type and elastane draw ratio on the elongation (\%) of denim fabrics is shown in Figure 1. 


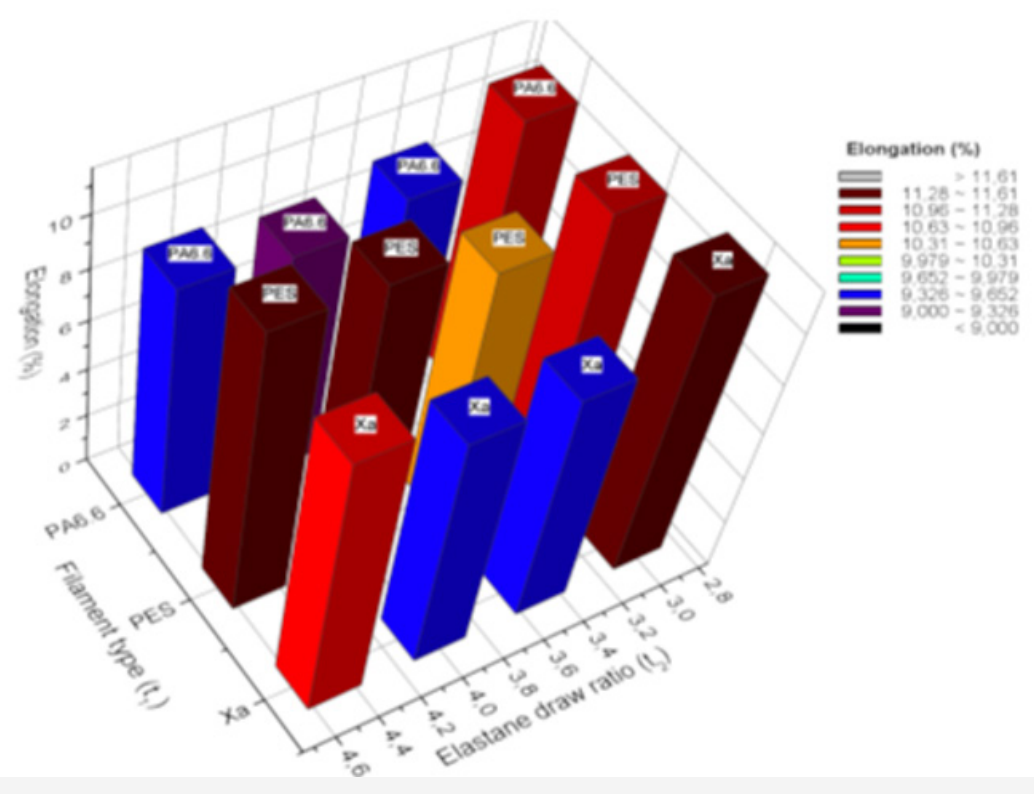

Figure 1: Thermal and evaporative resistance of the sleepwear fabrics.

Despite the fact that the warp yarns are the same, the weft yarns are different, so they have been different results on the elongation properties in the denim fabrics. It is a fact that the elongation ratio increases with the decrease of the elastane draw ratio [11]. However, a different situation arises here due to the type of filament. As can be seen in Figure 1, there is no steady increase or decrease tendency in elongation values depending on the change of the filament type and elastane draw ratio. While the highest elongation was observed in denim fabrics (1, 7 and 8), the lowest elongation was observed in denim fabric [12].

The change in the filament type was found to be statistically significant $(p<0.05)$, while the other factors $\left(t_{2}, t_{3}\right)$ were not

Table 7: Regression equations for denim fabric properties.

\begin{tabular}{|c|c|c|}
\hline Denim fabric properties & Regression equations & $\mathbf{R}^{2}(\%)$ \\
\hline Elongation (\%) & $10.983+0.248 \mathrm{t}_{1}+1.625 \mathrm{t}_{2}+1.84 \mathrm{t}_{3}-0.754 \mathrm{t}_{1}{ }^{2}+0.171 \mathrm{t}_{2}{ }^{2}+\mathrm{t}_{1}{ }^{*} \mathrm{t}_{2}+0.87 \mathrm{t}_{1}{ }^{*} \mathrm{t}_{3}$ & 77 \\
\hline Elasticity (\%) & $37.717-0.166 \mathrm{t}_{1}+0.98 \mathrm{t}_{2}-1.58 \mathrm{t}_{3}-0.720 \mathrm{t}_{1}{ }^{2}-1.971 \mathrm{t}_{2}{ }^{2}+9.64 \mathrm{t}_{1}{ }^{*} \mathrm{t}_{2}+11 \mathrm{t}_{1}{ }^{*} \mathrm{t}_{3}-2.222 \mathrm{t}_{1}{ }^{*} \mathrm{t}_{2}{ }^{*} \mathrm{t}_{3}$ & 92.64 \\
\hline Growth (\%) & $3.90-1.482 \mathrm{t}_{1}-0.781 \mathrm{t}_{2}-0.877 \mathrm{t}_{3}-0.514 \mathrm{t}_{1}{ }^{2}+0.514 \mathrm{t}_{2}{ }^{2}-2.623 \mathrm{t}_{1}{ }^{*} \mathrm{t}_{2}-2.787 \mathrm{t}_{1}{ }^{*} \mathrm{t}_{3}-0.296 \mathrm{t}_{1}{ }^{*} \mathrm{t}_{2}{ }^{*} \mathrm{t}_{3}$ & 95.93 \\
\hline Warp breaking strength (kgf) & $75.88+1.70 \mathrm{t}_{1}-23.31 \mathrm{t} 2-24.54 \mathrm{t}_{3}+2.571 \mathrm{t}_{1} 2+5.79 \mathrm{t}_{2} 2+14.43 \mathrm{t}_{1}{ }^{*} \mathrm{t}_{2}+14.92 \mathrm{t}_{1}{ }^{*} \mathrm{t}_{3}+2.22 \mathrm{t}_{1}{ }^{*} \mathrm{t}_{2}{ }^{*} \mathrm{t}_{3}$ & 72.06 \\
\hline Weft breaking strength (kgf) & $45.639+3.830 \mathrm{t}_{1}-0.73 \mathrm{t}_{2}-1.02 \mathrm{t}_{3}+0.543 \mathrm{t}_{1}{ }^{2}-0.143 \mathrm{t}_{2}{ }^{2}+9.26 \mathrm{t}_{1}{ }^{*} \mathrm{t}_{2}+9.62 \mathrm{t}_{1}{ }^{*} \mathrm{t}_{3}+2.469 \mathrm{t}_{1}{ }^{*} \mathrm{t}_{2}{ }^{*} \mathrm{t}_{3}$ & 75.83 \\
\hline $\begin{array}{c}\text { Finished fabric shrinkage in } \\
\text { warp direction (\%) }\end{array}$ & $-3.067+1.192 \mathrm{t}_{1}+2.402 \mathrm{t}_{2}+2.483 \mathrm{t}_{3}-0.911 \mathrm{t}_{1}{ }^{2}+0.04 \mathrm{t}_{2}{ }^{2}+0.83 \mathrm{t}_{1}{ }^{*} \mathrm{t}_{2}+0.5 \mathrm{t}_{1}{ }^{*} \mathrm{t}_{3}+0.29 \mathrm{t}_{1}{ }^{*} \mathrm{t}_{2}{ }^{*} \mathrm{t}_{3}$ & 88.8 \\
\hline $\begin{array}{c}\text { Finished fabric shrinkage in } \\
\text { weft direction (\%) }\end{array}$ & $-12.218+0.630 \mathrm{t}_{1}-1.55 \mathrm{t}_{2}-0.72 \mathrm{t}_{3}-0.863 \mathrm{t}_{1}{ }^{2}+0.679 \mathrm{t}_{2}{ }^{2}-6.09 \mathrm{t}_{1}{ }^{*} \mathrm{t}_{2}-6.93 \mathrm{t}_{1}{ }^{*} \mathrm{t}_{3}-1.123 \mathrm{t}_{1}{ }^{*} \mathrm{t}_{2}{ }^{*} \mathrm{t}_{3}$ & 89.28 \\
\hline
\end{tabular}

It is known for a fact that in fabrics produced with core-spun yarns containing only elastane, the elasticity increases with the increase of the ratio of elastane [13]. But here, in the status where the elastane ratio is the highest in the denim fabrics, the elasticity values are the lowest. It is shown in Figure 2. Since the filament used for this different situation is more rigid than the elastane, it can be interpreted that the tendency of elasticity is controlled by the type of filament. statistically significant (Table 6). The regression equation obtained for elongation (\%) is given below.

$$
\text { Elongation }(\%)=10.983+0.248 t_{1}-0.754 t_{1}{ }^{2}
$$
statistically significant were removed from the equation. Here, $\mathrm{R}^{2}$ value shows that $77 \%$ change of in the elongation can be explained by the variables $t_{1}, t_{2}$ and $t_{3}$ (Table 7 ). This equality shows that the change in filament type has a significant effect on the elongation properties of denim fabrics.

The effect of change in filament type and elastane draw ratio on the elasticity (\%) property of the denim fabrics is shown in Figure 2.
To make the equation more effective, terms that are not

It was found that denim fabric [5], which has better elongation properties, also has better dimensional stability under load. Therefore, it can be said that the use of elastic dual core-spun yarn in weft direction in denim fabrics will provide a great advantage in that elasticity is controllable, predictable and reducible. Although elasticity is a desirable feature at certain ratios, growth is an important problem, especially for denim fabrics. There are many previous studies on this subject. Increasing the amount of elastane 
used in the denim fabric has provided more comfort features, and with the increase in the ratio of elastane, the growth or the permanent elongation values of the denim fabrics were decreased up to $5.5 \%$ [1].

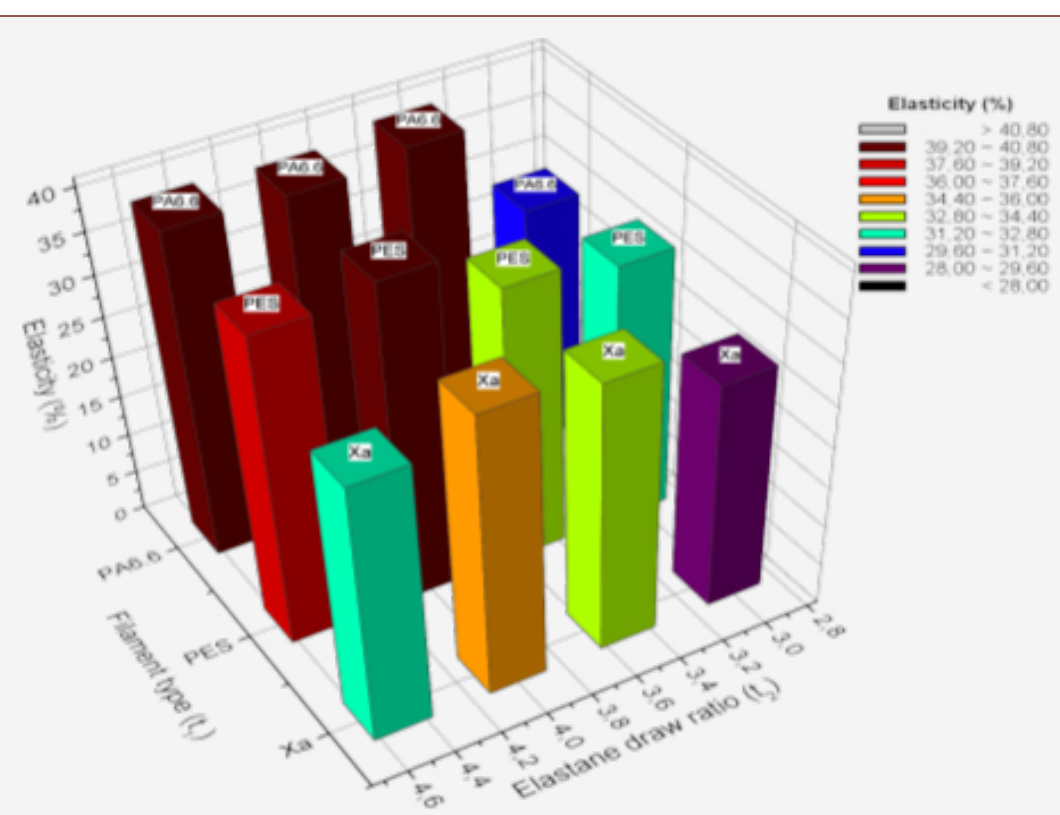

Figure 2: Elasticity (\%) of denim fabrics.

The effect of the change in filament type and elastane draw ratio on the growth (\%) property of the denim fabrics is shown in Figure 3.

It is seen in Figure 3 that the growth value of the denim fabrics is the highest $6 \%$ and the lowest is $2 \%$. The change in the elastane ratio in the sample denim fabrics did not show a regular tendency on the growth values. However, it is seen that has a very high improvement in the positive direction of the growth values of the denim fabrics depending on the change of the filament type.

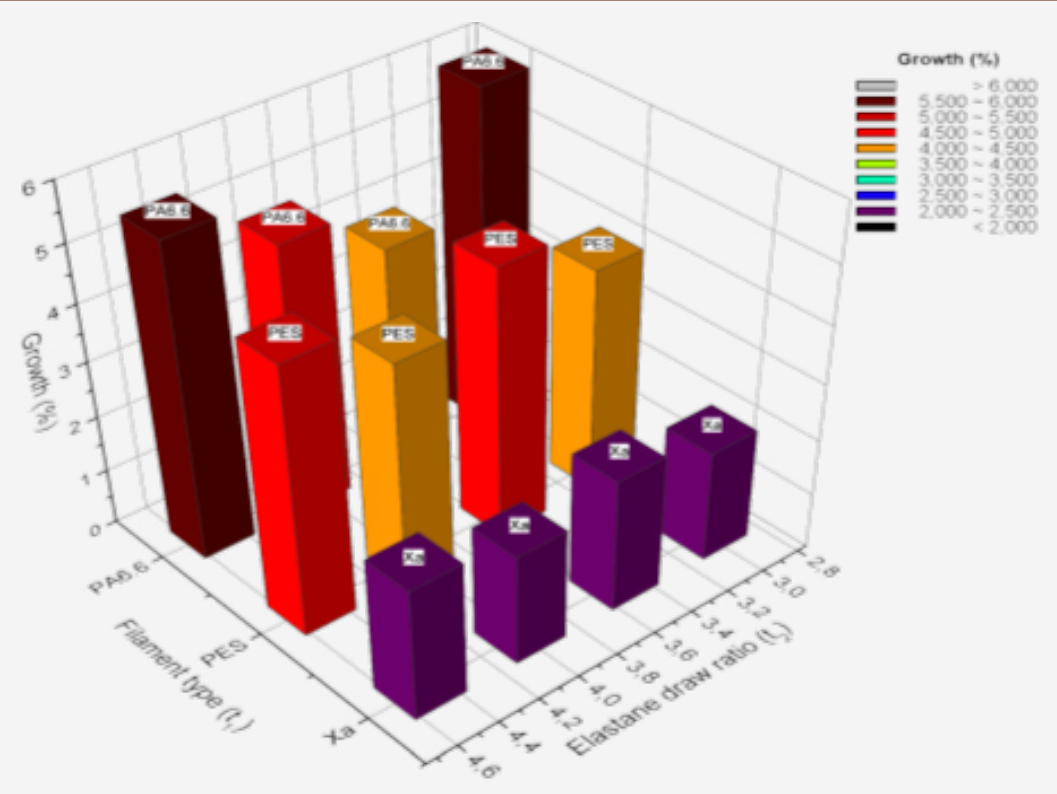

Figure 3: Growth (\%) of denim fabrics.

The lowest growth value was observed in denim fabric [2] containing xanadu filament yarn and $1.78 \%$ elastane. Xanadu is better than other filament types in terms of recovery properties [12]. Hence, the effect of the filament type on the growth values of denim fabrics produced by elastic dual core-spun weft yarns is great. It can be interpreted that the change in filament type shows a regular trend on the improvement of growth values.
For the elasticity, the interaction between the factors was statistically significant $(\mathrm{p}<0.05)$ and for growth, the change in the filament type and the interaction between the factors were statistically significant $(\mathrm{p}<0.05)$. The regression equations obtained for Elasticity (\%) and growth (\%) are given below $(3,4)$.

Elasticity $(\%)=37.717-0.720 t_{1}^{2}-1.971 t_{2}^{2}+9.64 t_{1} * t_{2}+11 t_{1} * t_{3}-2.222 t_{1} * t_{2} * t_{3}$ 
Growth $(\%)=3.90-1.482 t_{1}-0.514 t_{1}^{2}+0.514 t_{2}{ }^{2}-2.623 t_{1} * t_{2}-2.787 t_{1} * t_{3}-0.296 t_{1} * t_{2} * t_{3}$

To make the equation more effective, terms that are not statistically significant were removed from the equation. Here, $\mathrm{R}^{2}$ value shows that $92.64 \%$ change in the elasticity can be explained by the variables $t_{1}, t_{2}$ and $t_{3}$ (Table 7). Additionally, $R 2$ value for growth shows that $95.93 \%$ change in the growth can be explained by the variables $t_{1}, t_{2}$ and $t_{3}$ (Table 7 ).

As can be seen from the equations, it can be said that the interaction between process factors has an important influence on the elasticity and growth characteristics of denim fabrics. It is observed that the interaction between filament type $\left(t_{1}\right)$ and elastane ratio of fabric $\left(\mathrm{t}_{3}\right)$ is more effective on elasticity as shown in the equation (3). In addition, it is understood from the equation (4) that the filament type factor $\left(t_{1}\right)$ has a higher effect than the other factors in the decrease of the growth characteristic.

\section{Strength}

The effect of the change in filament type and elastane draw ratio on the breaking strength properties of the denim fabrics in the warp direction is shown in Figure 4.

The change in filament type and elastane draw ratio in the denim fabrics did not show a regular trend on the breaking strength in the warp direction. The lowest breaking strength in the warp direction was observed in denim fabric sample [9] containing 1.78\% elastane and with PES filament. The highest strength was observed in the denim fabric sample [13] containing 2.03\% elastane with the PA6.6 filament.

The effect of the change in filament type and elastane draw ratio on the breaking strength properties of the denim fabrics in the weft direction is shown in Figure 5.

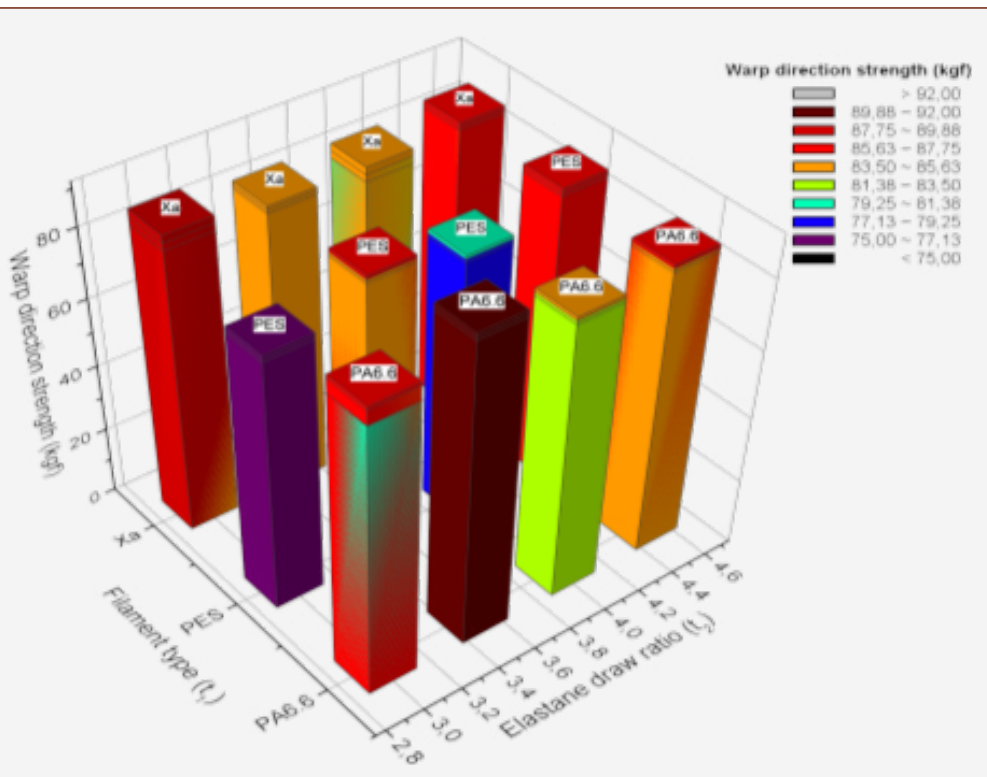

Figure 4: Weft breaking strength of denim fabrics.

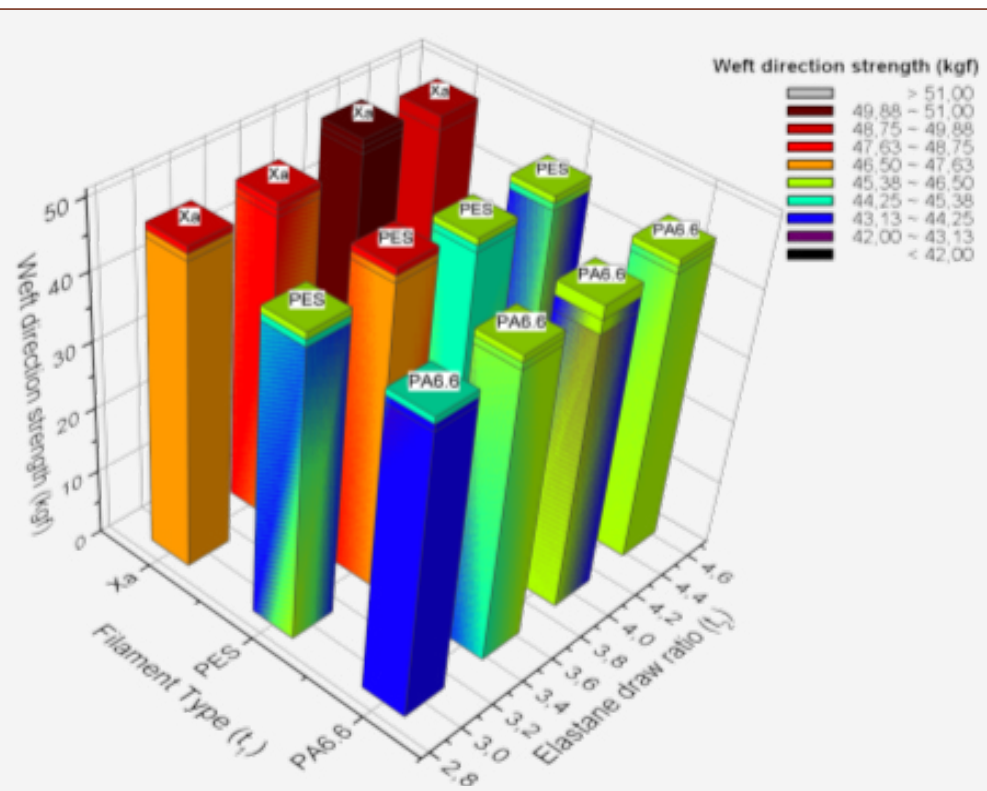

Figure 5: Weft breaking strength of denim fabrics. 
In denim fabrics using elastic dual core-spun yarn in the direction of the weft, different breaking strength values in the warp direction were observed. It is clear that this is due to the variables $\left(t_{1}, t_{2}, t_{3}\right)$ that are based on the study.

The change in the elastane ratio in the denim fabrics did not show a regular effect on the increasing or decreasing direction of the breaking strength in the weft direction. In addition, it is observed in Figure 5 that the change of the filament type and the regular trend of the breaking strength of the sample denim fabrics in the weft direction. The resistance of cotton fibers wrapping the elastic dual core-spun yarn $(3.56 \mathrm{~g} / \mathrm{d})$ is higher than that of elastane (1.09 g/d). However, the filament strength (Xa; $4.28 \mathrm{~g} / \mathrm{d}, \mathrm{PES} ; 3.96$ $\mathrm{g} / \mathrm{d}$, PA6.6; $4.30 \mathrm{~g} / \mathrm{d}$ ) is higher than both cotton fiber and elastane. Therefore, it can be said that there is a tendency depending on the filament type in the strength values. In addition, cotton, elastane and filament surface interaction will be greater because Xa is in a more curved structure. Thus, it is expected that fabrics produced with elastic dual core-spun yarns containing Xa and elastane have high strength in the weft direction.

Filament type $\left(\mathrm{t}_{1}\right)$, elastane draw ratio $\left(\mathrm{t}_{2}\right)$, and elastane ratio of fabric $\left(t_{3}\right)$ were selected as process factors. The interaction between factors other than the filament type $\left(t_{1}\right)$ and the factors was found statistically significant $(\mathrm{p}<0.05)$ for the strength in the direction of the warp. For strength in the weft direction, the change in the filament type $\left(t_{1}\right)$ and the interaction between the factors were statistically significant $(\mathrm{p}<0.05)$. Regression equations (5) and (6) obtained for strength in warp direction and strength in weft direction are given below.

Wrap Breaking strength $=75.88-23.31 t_{2}-24.54 t_{3}+2.571 t_{1}^{2}+5.79 t_{2}^{2}+14.43 t_{1} * t_{2}+14.92 t_{1} * t_{3}$
Weft breaking strength $=45.639+3.830 t_{1}+0.543 t_{1}^{2}-0.143 t_{2}{ }^{2}+9.26 t_{1} * t_{2}+9.62 t_{1} * t_{3}+2.469 t_{1} * t_{2} * t_{3}$

To make the equation more effective, terms that are not statistically significant were removed from the equation. $\mathrm{R}^{2}$ value for the breaking strength in the warp direction is $72.06 \%$. According to this, $72.06 \%$ of the breaking strength change in the warp direction can be explained with the $t_{1}, t_{2}$ and $t_{3}$ variables (Table 7.). For the breaking strength in the weft direction, $\mathrm{R}^{2}$ value being $75.83 \%$. According to this, $75.83 \%$ of the breaking strength change in the weft direction can be explained with $t_{1}, t_{2}$ and $t_{3}$ variables (Table 7).

As can be seen from the equations, it can be said that the interaction between process factors has a significant effect on the weft and warp strength of denim fabrics. In the denim fabric, the increase in elastane ratio is seen in equation (5), which affects the strength in the warp direction negatively. In addition, equation (6) shows that the interaction between the filament type $\left(t_{1}\right)$ and the elastane ratio of fabric $\left(t_{3}\right)$ is more effective on the strength in the weft direction.

\section{Shrinkage}

The effect of the change in filament type and elastane draw ratio on the shrinkage of denim fabrics in the warp direction is shown in Figure 6.

As seen in Figure 6, shrinkage in the warp direction was observed for all denim fabrics. The type of yarn used in the direction of the warp is the same. However, elastic dual core-spun yarns with different types only used in the direction of the weft have caused different shrinkage values to appear in the warp direction. The effect of the change in filament type and elastane draw ratio on the shrinkage of sample denim fabrics in the weft direction is shown in Figure 7.

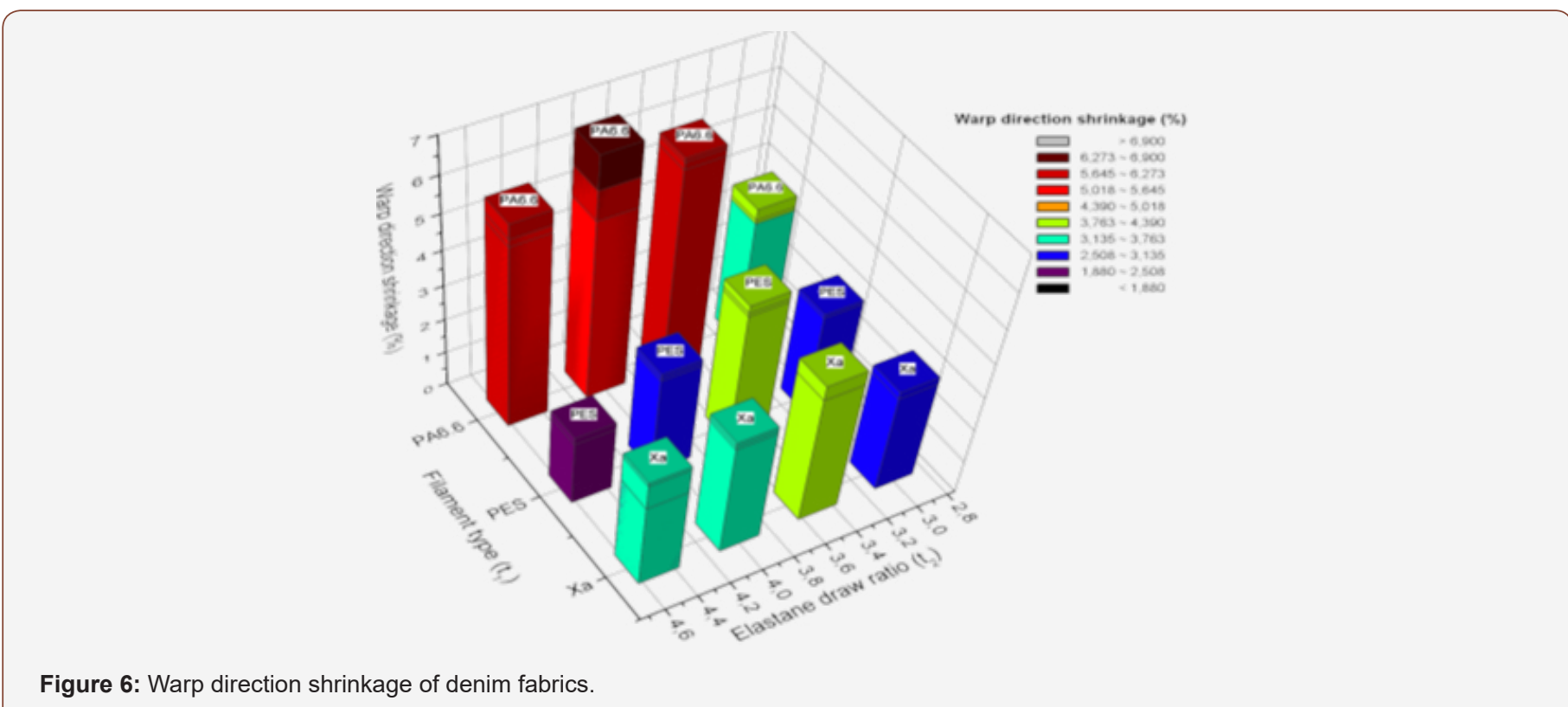

Figure 6: Warp direction shrinkage of denim fabrics.

As can be seen in Figures 6 and Figures 7, different shrinkage ratios in both warp and weft directions were found in denim fabrics due to different types of elastic dual core-spun weft yarns. In other studies, it was stated that as the elastane draw ratio decrease the shrinkage values decrease [11]. A similar situation emerged here. The lowest shrinkage values were observed in fabrics with 
the lowest elastane draw ratio. Also, the filament yarn, which has better dimensional stability than elastane, affected the dimensional stability of denim fabrics positively after the final operation. Hence, the joint effect of the change in elastane draw ratio $\left(t_{2}\right)$ and filament type $\left(t_{1}\right)$ decreased the shrinkage values of denim fabrics.

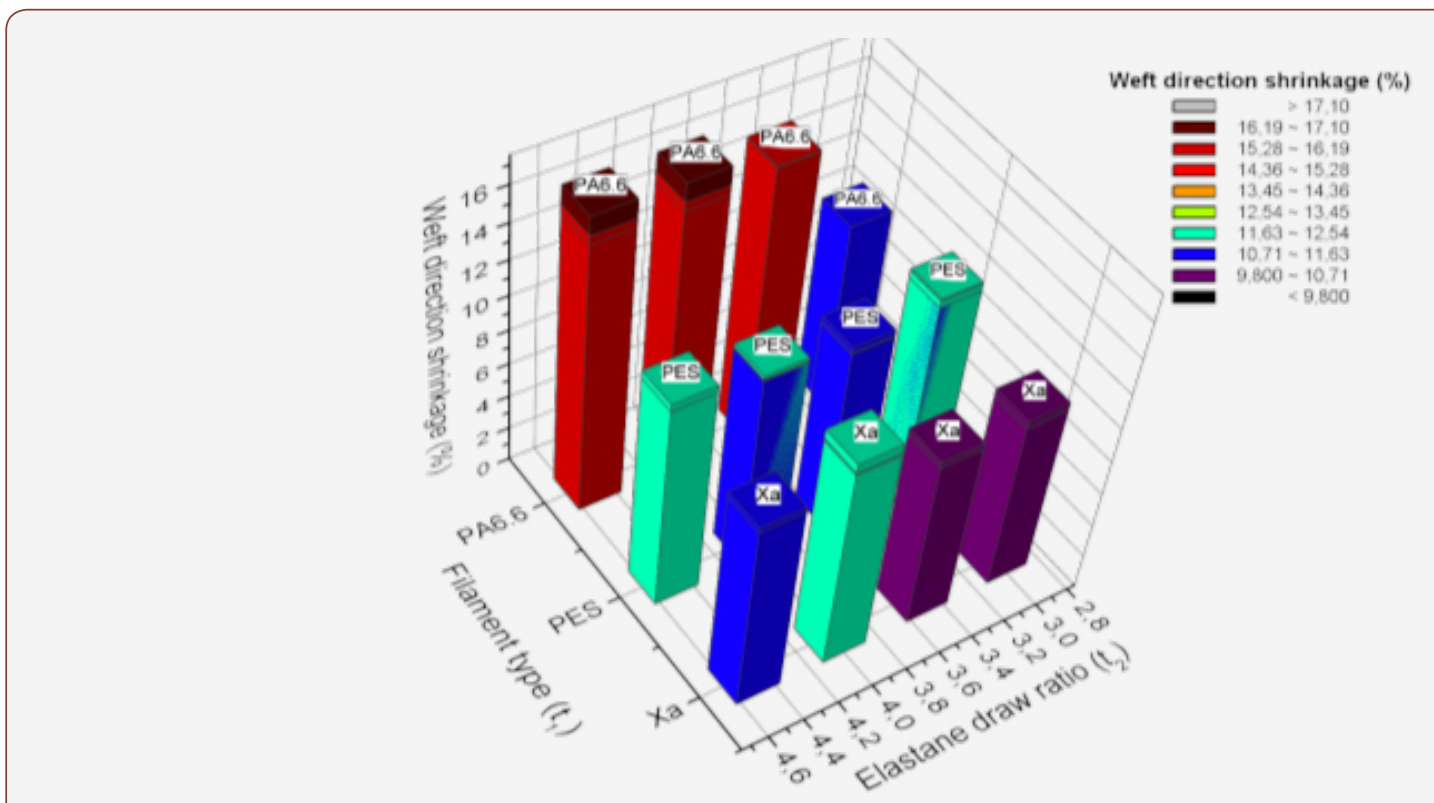

Figure 7: Warp direction shrinkage of denim fabrics.

When the process factors $\left(t_{1}, t_{2}\right.$ and $\left.t_{3}\right)$ were considered, all process factors for shrinkage in the warp direction were statistically significant $(\mathrm{p}<0.05)$. In the weft direction, the change $\left(t_{1}\right)$ in the type of filament and the interaction between the factors was statistically significant $(\mathrm{p}<0.05)$. The regression equations obtained for shrinkage in the warp direction and shrinkage in the weft direction are given below.

Shrinkage in warp direction $(\%)=-3.067+1.192 t_{1}+2.402 t_{2}+2.483 t_{3}-0.911 t_{1}^{2}$

Shrinkage in weft direction $(\%)=-12.218+0.630 t_{1}-0.863 t_{1}^{2}-6.09 t_{1} * t_{2}-6.93 t_{1} * t_{3}-1.123 t_{1} * t_{2} * t_{3}$

To make the equation more effective, terms that are not statistically significant were removed from the equation. $\mathrm{R}^{2}$ value for the shrinkage in the warp direction is $88.80 \%$. According to this, $88.80 \%$ of the shrinkage change in the warp direction can be explained by the variables $t_{1}, t_{2}$ and $t_{3}$. For the shrinkage in the weft direction, $\mathrm{R}^{2}$ value being $89.28 \%$. According to this, $89.28 \%$ of the shrinkage change in the weft direction can be explained with the variables $t_{1}, t_{2}$ and $t_{3}$. As can be seen from the equations, it can be said that the interaction between process factors has an important influence on the dimensional change in the weft and warp direction of denim fabrics. In addition, it was found that the elastane ratio of fabric ( $\mathrm{t} 3$ ) factor has a greater effect on the shrinkage values of the denim fabrics.

\section{Conclusion}

In this study, performance characteristics of denim fabrics produced by using elastic dual core-spun yarns in the weft direction are investigated. Quadratic mathematical equations were developed by using multiple regression analysis method. Thus, the effects of the process factors $\left(t_{1}, t_{2}\right.$ and $\left.t_{3}\right)$ in denim fabric production are examined.

As a result of the study, it was observed that the growth values of the denim fabrics in which the elastic dual core-spun yarns with filament and elastane in the core used in the weft direction are positively affected. Using core-spun yarn in weft direction, growth rates reached 5-6\% [1]. With the use of elastic dual core-spun yarn, it was reduced up to $2 \%$.

In addition, the stability in the elasticity/growth ratio is considered an important feature in denim fabrics. The best elasticity/growth value was seen in denim fabric containing $1.78 \%$ elastane with Xa filament. As a result, it proved that denim fabrics with low growth values can be produced, besides having a flexible structure [14].

The result of the formation of a conformable structure of filament, elastane and cotton fiber, the ability of the denim fabrics produced with elastic dual core-spun yarns to stretch in the linear direction increased. In addition, the shrinkage values at $18-20 \%$ were reduced up to $10 \%$ [15].

In addition, the strength of filament yarn compared to cotton and elastane makes it advantageous to produce more durable denim fabrics. Especially, the interaction between process factors $\left(t_{1}\right.$ and $t_{3}$ ) be quite effect on the strength in the weft direction shows that can be produce of more flexible and durable denim fabrics by increased the weft density.

In general, the results obtained in the study comply with the literature. In addition, different information that was not found in the literature regarding, the performance characteristics of denim 
fabrics produced with dual core-spun yarns using the combination of elastane and filament has been provided to the literature.

\section{Acknowledgement}

This work was supported by Scientific Research Projects Governing Unit (BAP) of Çukurova University [project ID: FBA2017-8446]. Authors are also grateful to ÇALIK DENIM AŞ for their support during project.

\section{Conflict of Interest}

Authors declare no conflict of interest.

\section{References}

1. Özdil N (2008) Stretch and bagging properties of denim fabrics containing different rates of elastane. Fibres \& Textiles in Eastern Europe 16(1): 63-67.

2. Baykus D (2003) Evaluation of Performance Determination and Improvement Methods in Woven Textile Products Containing Elastane. Master's thesis, Adana, Turkey.

3. Babaarslan O, Balcı H, Güler Ö (2007) Effect of elastane on the properties of Pes/Vis blend woven fabrics. Textile and Apparel 17(2): 110-114.

4. El-Ghezal S, Babay A, Dhouib S, Cheikhrouhou M (2009) Study of the impact of elastane's ratio and finishing process on the mechanical properties of stretch denim. Journal of the Textile Institute 100(3): 245253.

5. Adeli B, Ali Akbar G, Shanbeh M (2010) Structural evaluation of elastic core-spun yarns and fabrics under tensile fatigue loading. Textile Research Journal 81(2): 137-147.
6. Mourad M (2012) Physical and stretch properties of woven cotton fabrics containing different rates of spandex. Journal of American Science 8: 567-572.

7. Zhang J, Pan R, Wang J, Gao W, Han Y (2016) An efficient method for density measurement for high-tightness woven fabrics. Textile Research Journal 87(3): 329-339.

8. Zhang X, Li Y, Yeung KW, Yao, M (1999) Fabric Bagging: Part II: Objective Evaluation and Physical Mechanism. Textile Research Journal 69(8): 598-606.

9. Maqsood M, Hussain T, Ahmad N, Nawab Y (2016) Multi-response optimization of mechanical and comfort properties of bi-stretch woven fabrics using grey relational analysis in Taguchi method. The Journal of The Textile Institute 108(5): 794-802.

10. (2017) Hyosung Webpage.

11. Kaynak HK (2016) Optimization of stretch and recovery properties of woven stretch fabrics. Textile Research Journal 87(5): 582-592.

12. (2017) Toray Webpage.

13. Qadir MB, Hussain T, Malik M, Ahmad F, Jeong SH (2014) Effect of Elastane Denier and Draft Ratio of Core-Spun Cotton Weft Yarns on the Mechanical Properties of Woven Fabrics. Journal of Engineered Fibers and Fabrics 9(1): 23-31.

14. Sarığlu, E, Babaarslan O (2019) Porosity and air permeability relationship of denim fabrics produced using core-spun yarns with different filament finenesses for filling. Journal of Engineered Fibers and Fabrics 14: 1-8.

15. Babaarslan O, Sarıoglu E, Çelik Hİ, Avcı ME (2019) Denim Fabrics Woven with Dual Core-Spun Yarns. InTech Open. 